\title{
Editorial
}

\section{ENTRE A BALBÚRDIA E A BARBÁRIE DO SISTEMA CAPITAL: VAMOS À LUTA! ${ }^{1}$}

\author{
Eu acredito é na rapaziada \\ Que segue em frente \\ E segura o rojão \\ Eu ponho fé no pé da moçada \\ Que não foge da fera \\ E enfrenta o leão \\ Eu vou à luta com essajuventude \\ Que não corre da raia \\ À troco de nada \\ Eu vou no bloco \\ Dessa mocidade \\ Que não tá na saudade \\ E constrói a manhã desejada
}

E vamos à luta. Gonzaguinha, 1980.

Entre a última publicação da Revista Trabalho Necessário, em julho/2019 e a atual, também sobre Trabalho, movimentos sociais e educação, a conjuntura se complexificou no Brasil e no mundo. Fica claro a existência de dois grandes projetos societários: um projeto de acordo com os ditames do capital globalizado, do Deus Mercado, da competição e do individualismo, representado pela burguesia supranacional, tecido em um longo período histórico, que volta e meia, encontra-se em crise, pelas contradições por ele próprio gerado. Um sistema perverso e desumano, em que todos são tidos como mercadoria para alimentar a produção de bens materiais e imateriais, o consumo exacerbado e o lucro descomunal.

Como nos alerta Marx e Engels (1982, p.96), no Manifesto Comunista de 1848, "a burguesia [e seus representantes] não pode existir sem revolucionar constantemente os meios de produção e, por conseguinte, as relações de produção e, com elas, todas as relações sociais". O trabalho, em sentido histórico-ontológico, torna-se subsumido, pois "a burguesia despojou de sua 
auréola toda a ocupação até então considerada honrada e encarada com respeito. Converteu o médico, o jurista, o padre, o poeta, o homem de ciência em trabalhadores assalariados".

Contrahegemonicamente, no processo de disputa das classes sociais, temos outro projeto de construção societário, outra forma de encarar a formação humana, a humanidade, a vida, enfim, outra forma de conceber as relações sociais. Nesse processo de disputa, busca-se a transformação radical das relações sociais para a construção da democracia econômica, política e social, que possa garantir a formação e o convívio humanos de forma plena, em suas várias dimensões. Um projeto de sociedade baseado no respeito, na igualdade, na fraternidade, na liberdade, na solidariedade, onde os bens materiais e imateriais sejam comuns para todos os seres humanos. Que em sua relação com a natureza, não necessariamente a dominem, mas estabeleçam uma relação saudável e sustentável, entendendo-se como parte integrante dessanatureza.

E por que todo esse preâmbulo nesse editorial?

Porque, no plano ético-político, queremos deixar claro que, embora estejamos vivendo uma conjuntura extremamente adversa, o conjunto dos atores da universidade e dos setores da sociedade civil, principalmente os movimentos sociais comprometidos com a construção de uma sociedade justa, igualitária e fraterna, tem lutado, combatido e resistido, insistindo em dizer que um novo mundo é possível e necessário.

Neste cenário, onde a desesperança sangra corpos e mentes, queremos explicitar, antes de tudo, que possuímos projetos alternativos, sim, gestados coletivamente no seio da sociedade civil. Este é o compromisso que vem sendo firmado historicamente, em diferentes circunstâncias, pelos atores progressistas da sociedade, e que representa luta, discussão, vontade política, tensão, novas alternativas para os problemas de nossa sociedade, e porque não dizer, elementos potencializadores da construção de uma contra hegemonia.

Não pertencemos à liga dos sem esperanças e sem projetos alternativos ou, como nos diz Chico Buarque, "apesar de você, amanhã há de ser um outro dia...". Aqui, nos referimos à figura do atual ornitorrinco - um ser sem forma definida, mistura de Nero, Hitler, Profeta e Troglodita, que assumiu o poder executivo de nosso Estado-Nação em 2019, fazendo estragos em diferentes setores, a serviço do capital, em especial, dos EUA. 
Entre os estragos, estão os ataques às universidades e institutos de pesquisa, nos quais se produz conhecimento crítico, são socializados os saberes dos diferentes campos do conhecimento científico, acumulados pela humanidade e são formados quadros importantes para a sociedade. A política de cortes para funcionamento e manutenção de seus serviços, a saída em massa dos trabalhadores terceirizados, os cortes das bolsas de estudantes e pesquisadores e a proposta do Programa Future-se, do MEC (17 de julho de 2019) são ações concretas de desmonte da ciência no país.

Este Programa pode ser lido como fature-se, vire-se, fracione-se, na medida que busca fazer da universidade uma instituição que dependerá das necessidades do mercado, ferindo sua autonomia administrativa, financeira e acadêmica, garantida pela Constituição Federal de 1988. A saída proposta pelo Future-se é a iniciativa privada, por meio da captação de recursos. Tal medida fere o princípio da gratuidade e desresponsabiliza o Estado com a educação pública, tornando-a refém da iniciativa privada, sob a gestão das Organizações Sociais (OS), como destaca o documento do MEC:

O Future-se será operacionalizado por meio de contratos de gestão, firmados pela união e pelas ifes, com uma organização social, cujas atividades sejam dirigidas ao ensino, à pesquisa científica, à cultura e estejam relacionadas às finalidades do Programa. Os contratos de gestão poderão ser celebrados com organizações sociais já qualificadas pelos Ministério da Educação ou por outros ministérios, sem a necessidade de chamamento público, desde o escopo do trabalho esteja no âmbito do contrato de gestão já existente (Brasil, Ministério da Educação, 2019).

Segundo a ADUFF-SSind (2019) há uma lógica no Programa que atende aos interesses de grupos corporativos do campo da educação e do setor produtivo, na medida em que a educação superior passa a ser um negócio lucrativo. Assim, a proposta aponta para o fim do tripé ensino-pesquisa-extensão e corrói a diversidade e o caráter social e crítico das Ifes, tendo em vista que as pesquisas ditas como "não lucrativas" serão enfraquecidas ou terão sua continuidade interrompida. Ainda aponta a ADUFF,

O Future-se acaba com a Dedicação Exclusiva (DE), uma vez que apoiado no Novo Marco Legal de Ciência, Tecnologia e Inovação, prevê a possibilidade de docentes 
DE atuarem em projetos privados; essa medida abrirá caminho para o rebaixamento salarial das carreiras docentes, já em estudos pelo governo [ ] O Programa também aponta para o desmonte das carreiras do magistério superior, do ensino básico técnico e tecnológico (EBTT) e dos técnicos-administrativos, ao sinalizar para a cessão de atuais servidores para as organizações sociais e, ainda não mais através de concursos públicos, vinculado ao Regime Jurídico Único.

Não é somente a educação que vem sendo bombardeada, com vários projetos e reformas, mas todos os setores da sociedade, atingindo de forma cruel a classe trabalhadora e seus filhos. Para o bom entendedor é importante lembrar que as peças estão postas, mas não dadas definitivamente. A história não tem fim e os diferentes movimentos sociais populares e as mídias alternativas sabem disso. É com esse sentimento que têm sido elaboradas cartas públicas e abaixoassinados, dentre os quais destacamos a Carta de Salvador, construída no XVI Encontro Nacional da Associação Brasileira de Estudos do Trabalho - ABET e a Carta de Natal, construída no V Colóquio Nacional e II Colóquio Internacional A Produção do Conhecimento em Educação Profissional, ambas de 06/09/19, que publicizam, denunciam e anunciam os desafios postos no contexto social.

O Comunicado Popular das Centrais Sindicais, Movimentos Populares e Ambientais também fez um chamamento para a Greve Global pelo Clima, em 20/09/19. Ali estão sinalizadas paralisações, atos, ocupação das ruas, pela "defesa do meio ambiente, dos direitos sociais, trabalhistas e da soberania nacional, contra a destruição do Brasil, contra as queimadas e o desmatamento da Amazônia, pelo direito à aposentadoria digna, por geração de emprego e renda com todos os direitos garantidos e contra as privatizações de 17 estatais". Ainda podem ser agregados a luta contra a censura das manifestações artísticas e culturais; contra o anti-intelectualismo que menospreza o papel da ciência; a defesa da terra e do território dos indígenas e quilombolas contra posseiros, grilheiros, garimpeiros e militares, além das manifestações contra a violência no campo dos costumes e das sexualidades.

Em síntese, a balbúrdia e a barbárie do sistema capital fazem parte de uma mesma moeda, que visa atingir um contingente enorme da classe trabalhadora e de seus filhos/as. Contra esta balbúrdia, a nossa não significa desordem barulhenta, vozeria, algazarra, tumulto, trapalhada, complicação, 
situação confusa; como se apresenta na descrição do léxico na língua portuguesa. Significa sim, formação, disposição política e produção de conhecimento crítico, com a perspectiva de intervir com propriedade nos problemas concretos da sociedade, disponibilizando soluções reais para ela. A nossa balbúrdia é pelo enfrentamento da barbárie, da condição ou estado de bárbaro; barbarismo, selvageria. Significa, para nós, a luta contra a ausência de civilidade, de democracia e do respeito ao que é e deve ser comum para todos/as.

Esperamos que a TN 34 - Trabalho, movimentos sociais, educação II, seja inspiração para a luta cotidiana e necessária. Aqui, gostaríamos de fazer um agradecimento especial para todos aqueles e aquelas que construíram coletivamente este número, em especial a João Roberto Ripper, que nos cedeu a foto da capa, a qual retrata o comprometimento do fotógrafo com a vida e com a classe trabalhadora.

Voltamos a afirmar que o atual momento histórico precisa ser analisado com lucidez e com as "lentes necessárias" - da teoria, da filosofia, da política e da arte. Nosso instrumento de luta nas universidades e nos institutos de pesquisas é a construção do conhecimento crítico. Com as lentes das artes, como nos convoca Gonzaguinha, "vamos à luta!"

Boa leitura para tod@s!

Maria Cristina Paulo Rodrigues, Lia Tiriba, José Luiz Cordeiro Antunes Editores da Revista TN

\section{Referências}

Associação Docente da UFF-SSind. Com o Future-se e 'reformas', Bolsonaro quer destruir previdência, universidade pública e direitos. Niterói: Jornal da ADUFF-SSind, Julho de 2019.

BRASIL, Ministério da Educação. Programa Future-se. www.portal.mec.gov.br. Acessado em 17/09/2019.

MARX, K. Engels, F. O Manifesto Comunista de Marx e Engels. Rio de Janeiro: Zahar Editores, 1982. 